\title{
Doubly Fed Induction Generator and Conventional Synchronous Generator Based Power Plants: Operation during Grid Fault
}

\author{
M. B. C. Salles ${ }^{1}$, A. P. Grilo ${ }^{2}$ and J. R. Cardoso ${ }^{1}$ \\ ${ }^{1}$ LMAG - Laboratory of Applied Electromagnetism \\ PEA - Polytechnic School - University of São Paulo - Brazil \\ Phone/Fax number: +55 11 3091-5533, e-mail: mausalles@usp.br, jose.cardoso@poli.usp.br \\ ${ }^{2}$ Engineering, Modelling and Applied Social Science Center \\ Federal University of ABC, Great São Paulo - Brazil \\ Phone/Fax number: +55 11 3091-5533, e-mail: ahda.pavani@ufabc.edu.br
}

\begin{abstract}
The use of doubly fed induction generator in wind power plants has result in new necessities to maintain a reliable operation of the network. The tendency of the grid codes is to require the ability from the wind power plant to keep connected during and after grid disturbance, similarly to the synchronous generators requirements. This paper analyse the behaviour of a wind power plant equipped with doubly fed induction generators connected to a transmission system during grid fault and compare its performance with a conventional synchronous generator based power plant. The results have shown that the conventional synchronous generator has much more effective injection of reactive power during grid fault and, by consequence, the terminal voltage is kept in higher levels.
\end{abstract}

\section{Key words.}

wind power plant, doubly fed induction generator, transient stability, power system stability.

\section{Introduction}

The use of doubly fed induction generator (DFIG) has increased in the last 15 years [1]. The fast growing of wind power penetration in Europe and, more recently, in USA and China has changed the way that the Transmission System Operators (TSO's) administrates then power systems. In general, the fault tolerance of wind turbine generators tends to be equal to the conventional synchronous generator pushed by more restrictive grid codes [2]. They should not disconnect from the grid and they should contribute to the voltage regulation during and after faults. However, this is a task which depends on the specific characteristics of a certain power systems.

The conventional concept of synchronous generator (SG) is directly connected to the power system via a power transformer and the control of terminal voltage (or power factor) is by the field excitation. The rotor windings of the DFIG-based wind turbines are connected with the use of two back-to-back converters, while the stator windings are connected directly to the network via a power transformer. The control of terminal voltage (or power factor) by the DFIG is performed by the two back-toback converters. The rotor side converter (RSC) and also the grid side converter (GSC) can inject reactive power simultaneously. The investigation presented in this paper compares the performance of both power plants in order to better understand the positive and negative impacts on the stability and on the voltage regulation in a scenario accomplished to the new grid code requirements.

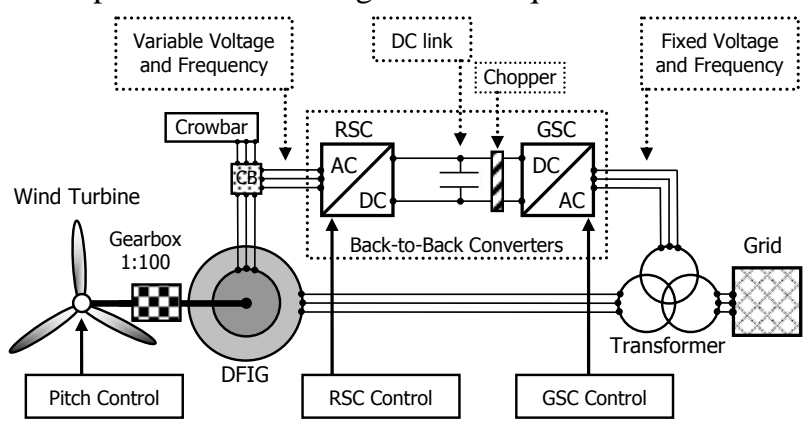

Fig. 1 Doubly fed induction generator (DFIG).

The dynamic models are developed using the Matlab/Simulink toolbox called SimPowerSystems. The phasor analysis was chosen as it is a common strategy for transient stability studies.

The paper sections are organized as follows. Section II discusses the aerodynamic model of the wind turbine. Section III describes the DFIG model. The test system is shown in Section IV. The comparative responses between the SG and the DFIG during grid faults are presented in Section V. The conclusions are discussed in Section VI.

\section{Aerodynamic Model of the Wind Turbine}

The aerodynamic model of the power capture from the wind is implemented using the well-know equation [3]:

$$
P_{m}=\frac{1}{2} A \rho V^{3} C_{P}(\lambda, \beta)
$$

where $A$ is the turbine rotor area, $\rho$ is the density of the air, $V$ is the wind speed, $C_{p}$ is the performance coefficient, $\beta$ is the blade pitch angle, $\lambda=\omega R / V$ is the tip speed ratio, $R$ is the radius of the rotor and $\omega$ is the angular speed of the blades.

\section{Doubly Fed Induction Generator (DFIG)}

This model comprises the electric generator and the converter controllers involved in the technologies. The power electronics are considered ideal, in this case the voltage reference signals determined by the controller is 
directly applied to the converters. The Fig. 1 shows a schematic diagram of the DFIG. The DFIG parameters used in this analysis are taken from a real machine detailed in [3].

There are two conventional modes of wind turbine operation considered in these analyses: normal mode operation and fault mode operation.

\section{A. Normal Mode Operation}

The normal mode operation is described below:

1) For wind speed smaller than the nominal

- Rotor side converter (RSC) controls the speed of the generator to follow the maximum energy extraction (speed is variable) and the power factor.

- The blade pitch angle control is set to $0^{\circ}$ (maximum energy capture).

- Grid side controller regulates the DC link voltage between the two converters in a fixed point.

2) For wind speed greater than the nominal

- Rotor side converter (RSC) controls the speed of the generator to a fixed point.

- The blade pitch angle is controlled to limit the energy capture from the wind in order to do not overcome the generator nominal characteristic.

- Grid side converter (GSC) regulates the DC link voltage between the two converters.

\section{B. Fault Mode Operation}

As commented before, the new grid codes require from the wind farms to keep connected during and after grid faults and support terminal voltage [4],[5]. Some methodologies have been proposed in the literature to follow these new requirements [6],[7], most of then are about methodologies of reactive power injection.

Some undesirable high currents may be induced in the rotor windings because the stator windings of the DFIG are directly connected to the network. In conventional DFIG (without fault ride through), the protection system may block the RSC. However, the DFIG with fault ride through is equipped with a crowbar system to limit the high induced currents on the rotor windings. The voltage at the DC-link is another undesirable transient, which can reach high levels, related to the unbalance of active power between RSC and GSC. The very low residual terminal voltage during the fault and the slow velocity of the RSC disconnection from the rotor winding, after fault detection, would cause such unbalance.

The crowbar system transforms the DFIG behaviour in a conventional squirrel-cage induction generator expanding the rotor critical speed for the period of the RSC disconnection from the rotor winding [8]. The chopper system is used to dissipate the unbalance of active power between RSC and GSC. Both of these devices can be seen in Fig. 1.

The fault mode operation is started after fault detection, the process is described below:
- The RSC is blocked and a crowbar system is inserted in series with the rotor windings. The machine operates as a squirrel-cage induction generator.

- The GSC starts to control reactive power during the fault and keep the voltage control of the DC link.

- The blade pitch angle is set to diminish the energy capture from the wind and, by consequence, the active power unbalance.

- RSC is restarted and crowbar protection is removed after $100 \mathrm{~ms}$ of the fault detection.

- Rotor side converter (RSC) returns to control the speed of the generator to a fixed point (the last measured speed before the fault).

- $\quad$ The fault is eliminated.

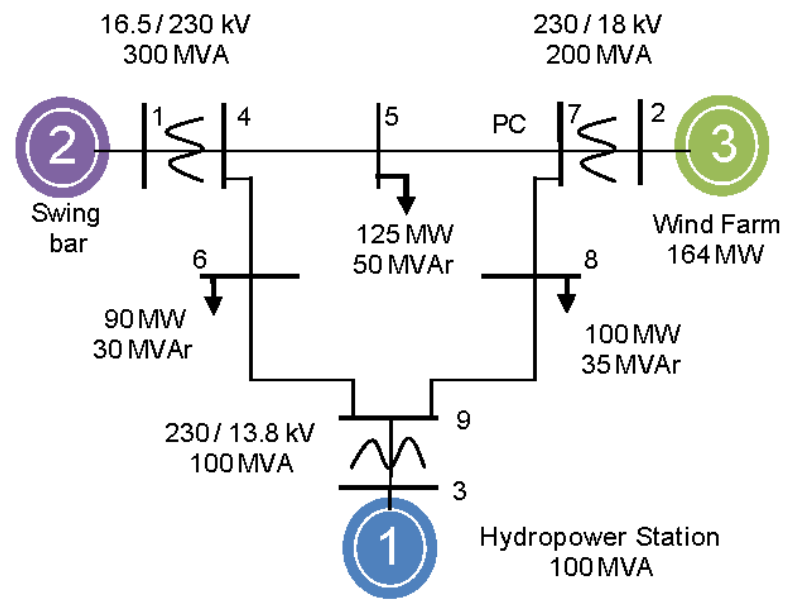

Fig. 2 Transmission system used for the analyses.

\section{Description of the Computational Models}

The representation of the network components are implemented by three-phase phasor models. The loads are considered constant impedances and transformers are represented by the $\mathrm{T}$ circuit. The test transmission system (shown in Fig. 2) is an adaptation of an American Transmission System (WSCC-9), the original data of this system can be found in [9].

The doubly fed induction generator (DFIG) and the synchronous generator are represented by the algebraicdifferential model in the $d q$ reference frame, as addressed in [10]. The converter controllers of the DFIG have a complex model corresponding to each mode of operating described in section 3. The IGBT based converters are considerate ideals. The controllers are described in the following subsection.

\section{A. Control of the Rotor-Side Converter (RSC)}

In normal mode operation, the rotor-side converter controls the injection of reactive power and the developed electric power $\left(P_{\text {elec }}\right)$. In fact, the maximum electric power depends on the rotor speed and on the incoming wind. In this operation point the optimum electric power reference $\left(P^{*}{ }_{\text {opt }}\right)$ is calculated taking into account the optimal rotor speed for the incoming wind by 
the maximum value of the $C p$ curves. In Fig. 3, the control used in the simulations is shown.

An encoder can give the generator rotor position $(\theta)$ to the abc-dq0 and to the dq0-abc transformations. The direct axis component is used to maintain the generator power factor in 1 pu thus, the absorbed reactive power reference $\left(Q^{*}\right)$ is equal to 0 (zero). The quadrature axis component is controlled in a similar way of the direct axis, however, it regulates the electric power to the optimal value $\left(P_{\text {opt }}^{*}\right)$. The $V_{d}^{*}$ and $V_{q}^{*}$ reference signals are send to the dq0-to-abc transformation and, then, to the signal generator based on the PWM (Pulse-width Modulation) methodology. Finally, $V_{a b c r}^{*}$ are the threephase voltages desired at RSC output.

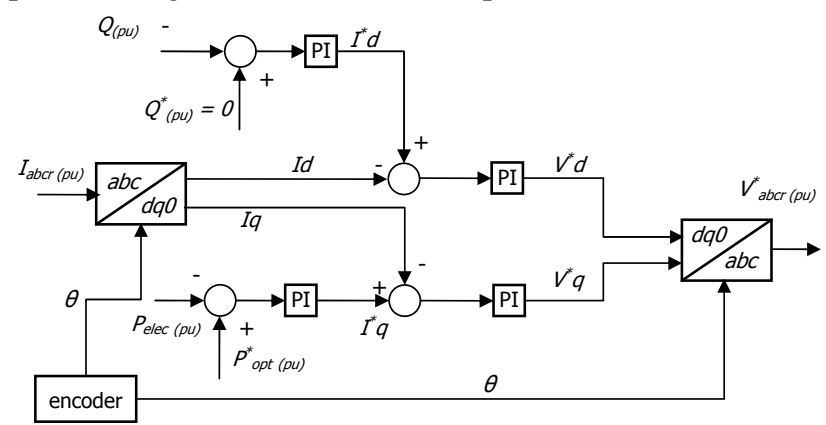

Fig. 3 RSC controller diagram for normal mode operation.

In fault mode operation, the crowbar system is required. When the terminal voltage suddenly drops to a value below $0.8 \mathrm{pu}$, the normal mode operation control scheme is stopped and the three-phase series resistance (crowbar system) is connected to the rotor windings by the circuit breaker (CB) shown in Fig. 1.

\section{B. Control of the Grid-Side Converter (GSC)}

In normal mode operation, the GSC control regulates the voltage of the DC link between RSC and GSC. In fact, controlling this voltage is another way of doing the control of the active power produced in the rotor windings. Fig. 4 shows the schematic diagram of the GSC control in normal mode operation.

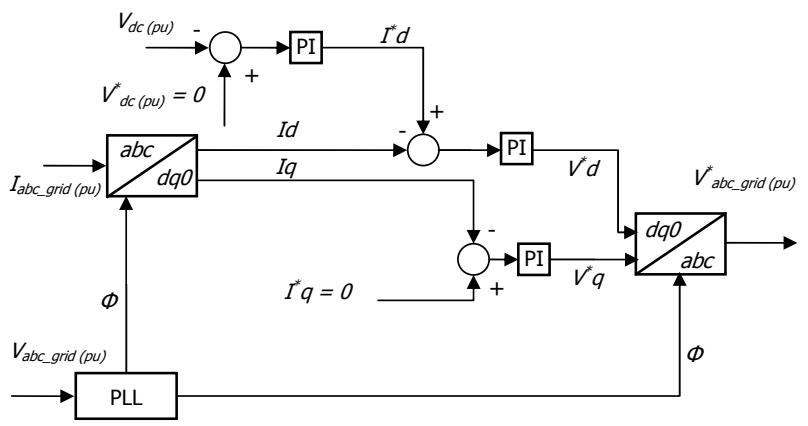

Fig. 4 GSC controller diagram for normal mode operation.

The controller employs a PLL (Phase Locked Loop) to provide the angle $(\phi)$ to the abc-to-dq0 (and dq0-to-abc) transformation. This angle gives the reference to the synchronization of the three-phase voltages of the converter output with the terminal voltage. The direct axis component is used to regulate the DC link voltage
$\left(V_{d c}^{*}\right)$ to 1 pu. The quadrature axis component of the reference current is set to zero $\left(I_{q}^{*}=0\right)$ since the power factor control is already been doing by the RSC. The $V^{*}$ and the $V_{q}^{*}$ references signals are sent to the dq0-to-abc transformation, then, to the PWM signal generator. Finally, $V_{a b c \_ \text {grid }}^{*}$ are the three-phase voltages desired at the grid-side converter output.

In fault mode operation, the voltage of the DC link can reach high level depends on the active power unbalance between RSC and GSC. This unbalance can be greater for low the residual terminal voltage during fault and for slowly disconnection of the RSC from the rotor winding after fault detection. The use of the DC chopper can dissipate the power unbalance, however, the GSC maintains the control of the DC link voltage in the same time. After the fault detection, GSC switches the the quadrature axis current reference $\left(I_{q}^{*}=0\right)$ to terminal voltage control.

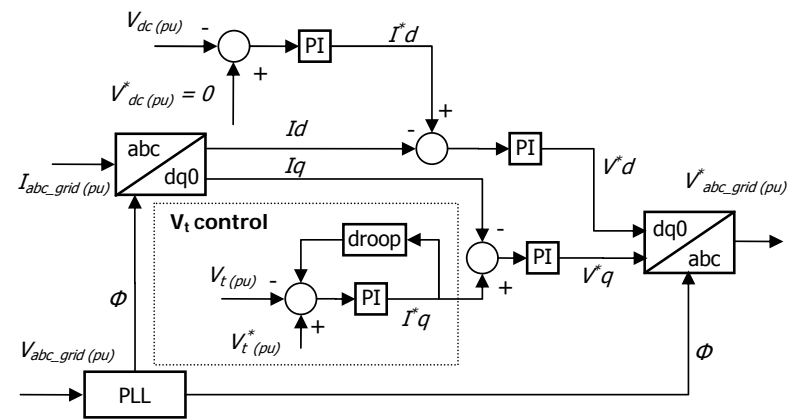

Fig. 5 GSC control diagram in fault mode operation.

In Fig. 5, one can see the addition of this part of the control, which enables the injection of reactive power into the network by the GSC. In this period, the DFIG inject reactive power via the GSC and, after the disconnection of the crowbar system, via RSC and GSC.

\section{Simulation Results}

The simulation results obtained from the analyses are presented in this section. The performances of both generators during a three-phase short circuit at Bus 5 for different fault clearance times (100 and $200 \mathrm{~ms}$ ) are presented in Fig. 6 to Fig. 13.

\section{A. Fault Clearance in 100ms}

When the short circuit is eliminated in $100 \mathrm{~ms}$, the voltages at Bus 5 are very similar for SG and for DFIG (Fig. 6). However, the voltage at Bus 7 and Bus 9 are higher for the SG (Fig. 7 and Fig. 8). This fact can be explained because the RSC of the DFIG is blocked during the complete fault time.

While the rotor windings are connected to the crowbar system, only the GSC is capable to inject reactive power into the grid limiting the effectiveness of the voltage control (Fig. 9). The SG can inject reactive power during the complete fault period, this fact enable higher voltage levels at the Buses in the neighbor of Bus 7. The injection of reactive power at Bus 9 elevates its voltage level. 


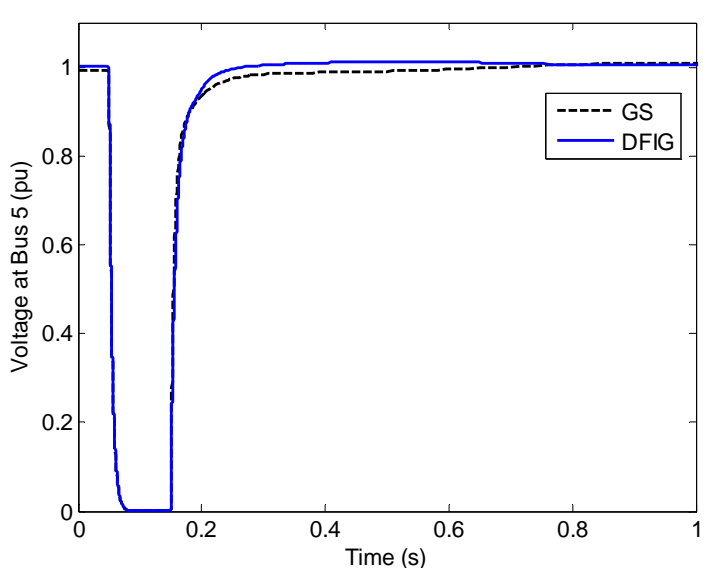

Fig. 6 Terminal voltage at bus 5 during a $100 \mathrm{~ms}$ fault.

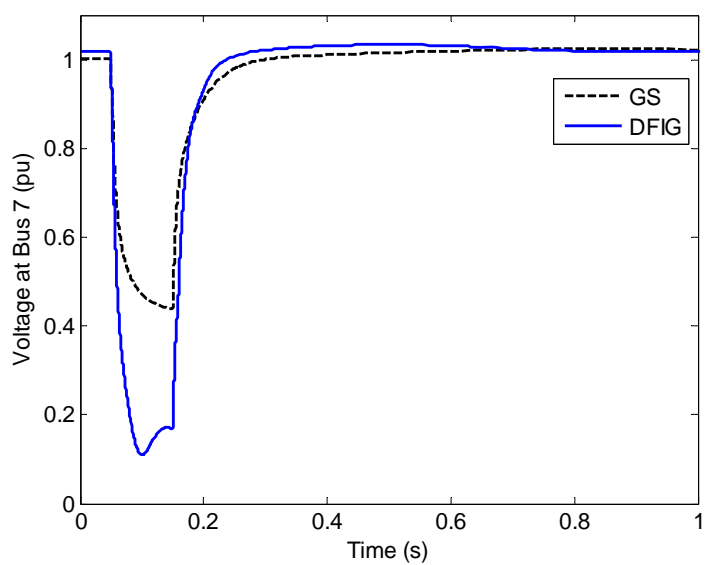

Fig. 7 Terminal voltage at bus 7 during a $100 \mathrm{~ms}$ fault.

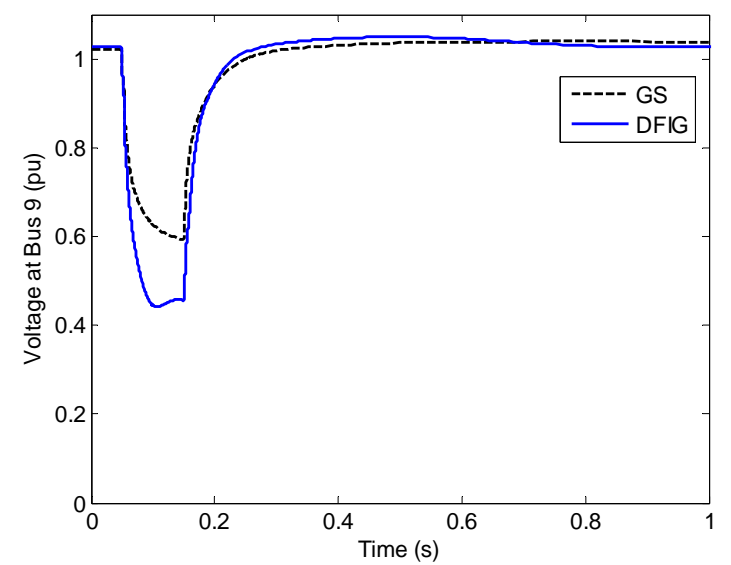

Fig. 8 Terminal voltage at bus 9 during a $100 \mathrm{~ms}$ fault

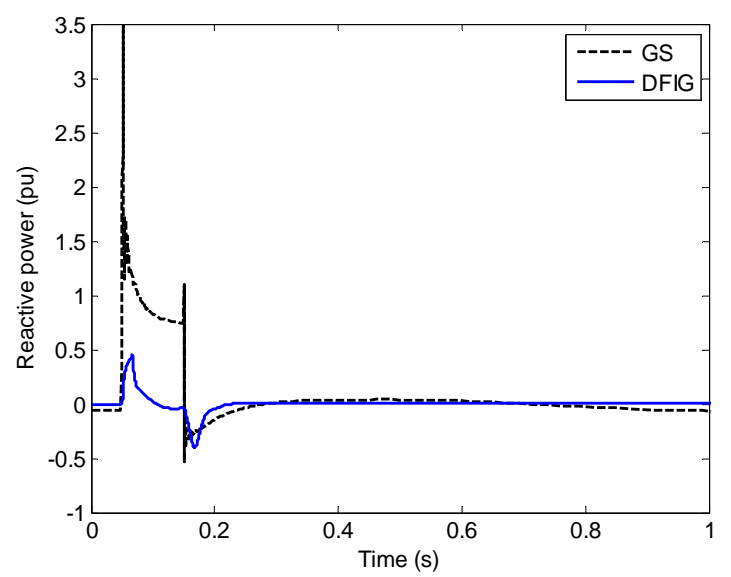

Fig. 9 Reactive power at bus 7 during a $100 \mathrm{~ms}$ fault.

\section{B. Fault Clearance in $200 \mathrm{~ms}$}

A short circuit eliminated in $200 \mathrm{~ms}$ affect the voltage at Bus 5 in a similarly way (Fig. 10) for both generators. In this case, we can note that the voltage at Bus 7 and Bus 9 for the DFIG based power plant has improved the maximum voltage value during the fault while the behavior of the SG has maintained basically the same (Fig. 11 and Fig. 12).

We clearly see that the DFIG is not effectively injecting reactive power during the first 100 milliseconds after the fault detection. This is the period which the crowbar system is in operation and only the GSC injects a limited amount of reactive power. After this period, the RSC is reconnected to the rotor windings and the reactive power injection by this converter is restarted (Fig. 13), improving the voltage level during the fault (Fig. 11 and Fig. 12).

The synchronous generator (SG) corresponds to the highest level of terminal voltage. There are two reasons to explain the better performance of the SG:

- No interruption of the reactive power injection.

- Higher reactive power injection during the fault.

The SG injects a higher value of reactive power which is limited only by the nominal characteristic of the field excitation. The limit for the DFIG is the nominal characteristics of the converters and the period of protective devices operation.

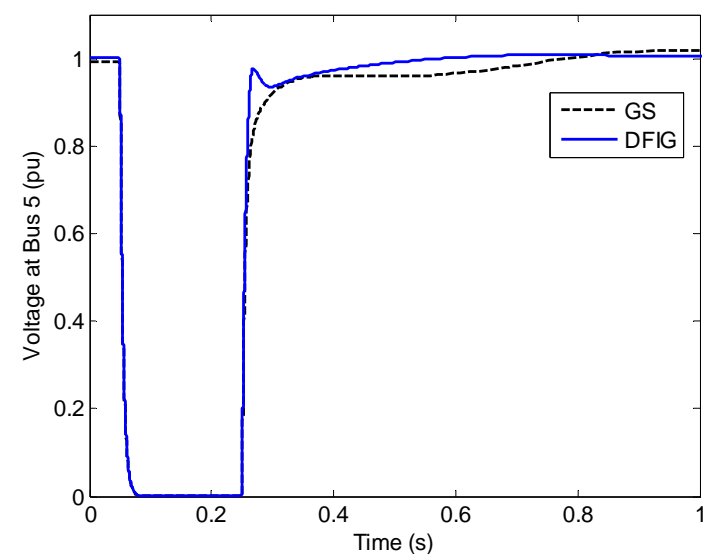

Fig. 10 Terminal voltage at bus 5 during a $200 \mathrm{~ms}$ fault.

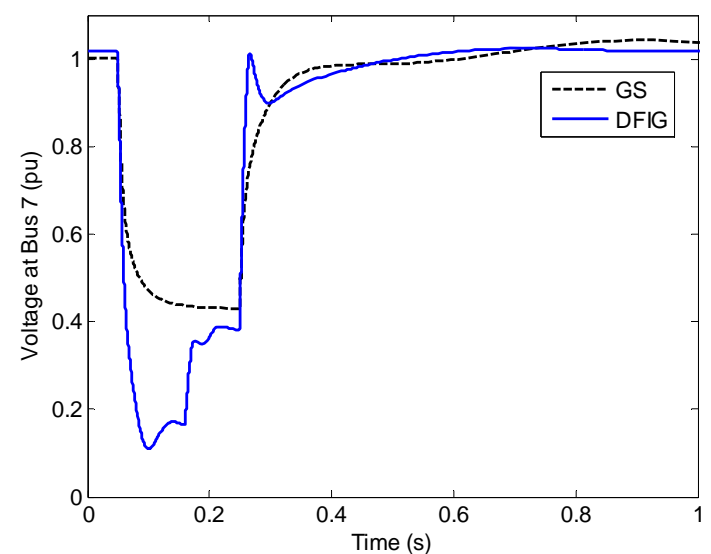

Fig. 11 Terminal voltage at bus 7 during a $200 \mathrm{~ms}$ fault. 


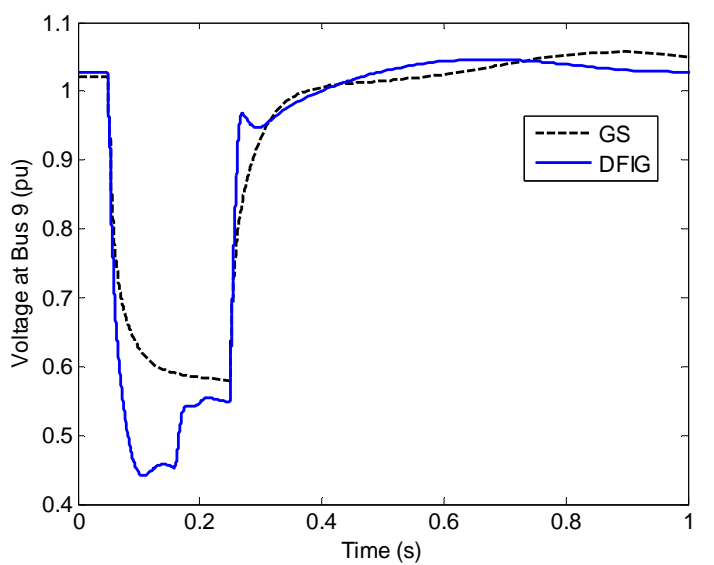

Fig. 12 Terminal voltage at bus 9 during a $200 \mathrm{~ms}$ fault.

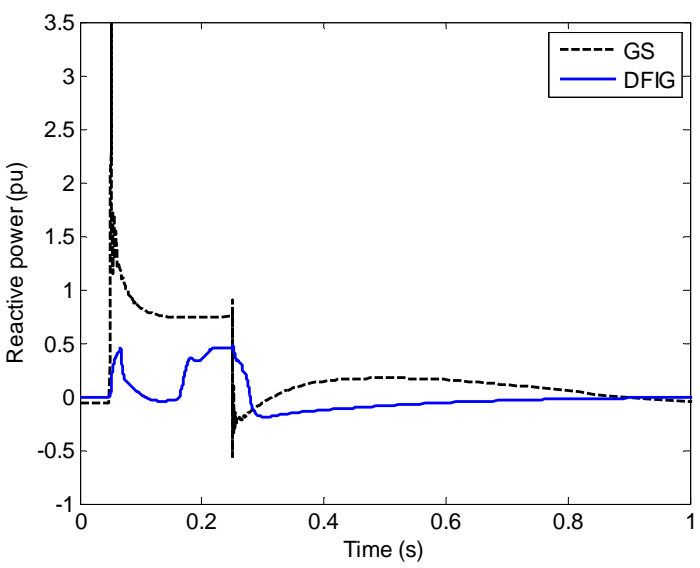

Fig. 13 Reactive power at bus 7 during a $200 \mathrm{~ms}$ fault.

\section{Conclusion}

The comparison between DFIG and SG operating during grid fault is proposed in this paper. The results are presented and discussed considering the performance of terminal voltages and the reactive power injections. The DFIG has some limitations to control the terminal voltage during fault, however, it can operate without disconnecting from the network. The operation period of the crowbar system affect considerably the injection of reactive power in the network. This protective device is essential to guarantee the safe operation during short circuits on the network.

\section{Acknowledgement}

The authors gratefully acknowledge the financial support from the Brazilian government via FAPESP (State of São Paulo Research Foundation).

\section{References}

[1] H. Li, Z. Chen, "Overview of Different Wind Generator Systems and their Comparisons", IET Renewable Power Generation, vol. 2, no. 2, pp. 123-138, 2008.

[2] R. Piwko, N. Miller, R. Girad, J. MacDowell, K. Clark, A. Murdoch, "Generator Fault Tolerance and Grid Codes", IEEE Power and Energy Magazine, vol.8, no. 2, pp. 18-26, March-April, 2010.

[3] J. G. Slootweg; H. Polinder; W. L. Kling, "Representing Wind Turbine Electrical Generating Systems in Fundamental Frequency Simulations”, IEEE Transactions on Energy Conversion, vol. 18, no.4, pp. 516-524, 2003.

[4] Grid Code: High and Extra High Voltage, E.ON Netz GmbH Tech. Rep., Status: 1, 2006.

[5] P.O. 12.3 "Requisitos de Respuesta frente a Huecos de Tensión de las Instalaciones Eólicas" (in Spanish), BOE no. 254, pp. 37017-37019, October 24th 2006.

[6] Mustafa Kayıkc,1 and Jovica V. Milanovi'c, "Reactive Power Control Strategies for DFIG-Based Plants”, IEEE Transactions on Energy Conversion, vol. 22, no. 2, 2007.

[7] N.R. Ullah, T. Thiringer, D. Karlsson, "Voltage and Transient Stability Support by Wind Farms Complying With the E.ON Netz Grid Code”, IEEE Transactions on Power Systems, vol. 22, no. 4, pp. 1647-1656, 2007.

[8] A. P. Grilo, A. A. Mota, L. T. M. Mota, W. Freitas, “An Analytical Method for Analysis of Large-Disturbance Stability of Induction Generators", IEEE Transactions on Power Systems, v. 22, p. 1861-1869, 2007.

[9] P. W. Sauer and M.A. Pai, Power System Dynamics and Stability, Prentice Hall, Upper Saddle River, NJ, 1998.

[10] P. Kundur, Power System Stability and Control. New York: McGraw-Hill, 1994. 